\title{
Revisão das Complicações da Utilização da Toxina Botulínica Full Face
}

\section{Review of Complications of Using Full Face Botulinum Toxin}

DOI: $10.46919 / \operatorname{archv1n6-018}$

Recebimento dos originais: 01/09/2020

Aceitação para publicação: 30/10/2020

\author{
Adriana Novaes Rodrigues \\ Doutora em Ciência pela Universidade de São Paulo \\ Instituição: Universidade de São Paulo \\ Endereço: Av. Dr. Arnaldo, 455 - Cerqueira César • CEP: 01246903 • São Paulo - SP - Brasil. \\ E-mail: a.novaes@live.com \\ Maria Fernanda Maluf Novaes Franco \\ Graduanda em Medicina \\ Instituição: Centro Universitário Barão de Mauá \\ Endereço: R. Ramos de Azevedo, 423 - Jardim Paulista, Ribeirão Preto - SP, 14090-062 \\ E-mail: mariafernanda.vest19@outlook.com
}

\begin{abstract}
RESUMO
Introdução: A toxina botulínica (BoNT) é uma neurotoxina produzida pelo Clostridium botulinum, Dentre os oito tipos de neurotoxinas, a do tipo A, sendo a mais utilizada. Entretanto, alguns riscos e possíveis complicações decorrentes do uso dessa substância podem acontecer Objetivo: Revisar a literatura abordando os eventos adversos decorrentes do uso da BoNT. Resultados: apesar de ser um procedimento considerado seguro e minimamente invasivo, a aplicação da BoNT pode causar algumas complicações leves a graves. Conclusão: É fundamental que os profissionais envolvidos neste procedimento, saibam reconhecer e intervir nas possíveis complicações.
\end{abstract}

Palavras-chave: Toxina Botulínica, Complicações, Neuro toxinas, Estética.

\begin{abstract}
Introduction: Botulinum toxin (BoNT) is a neurotoxin produced by Clostridium botulinum. Among the eight types of neurotoxins, type A, the most used. However, some risks and possible complications resulting from the use of this substance can happen Objective: To review the literature addressing the adverse events resulting from the use of BoNT. Results Despite being a procedure considered safe and minimally invasive, the application of BoNT can cause some mild to severe complications. Conclusion: It is essential that the professionals involved in this procedure, know how to recognize and intervene in possible complications.
\end{abstract}

Keyword: Botulinum Toxin, Complications, Neuro toxins, Aesthetics.

\section{INTRODUÇÃO}

Produzida pela bactéria anaeróbia Clostridium botulinum, a toxina botulínica (BoNT), foi a primeira proteína microbiana a ser utilizada de forma injetável para tratamento de diversas patologias ${ }^{1}$. Foi desenvolvida inicialmente, em laboratórios de guerra ${ }^{2}$. Estruturalmente, os BoNT consistem em 
cadeias polipeptídicas leves e pesadas de cerca de 100 e $50 \mathrm{kDa}$ de tamanho, respectivamente, acopladas por uma ponte dissulfeto ${ }^{3}$.A cadeia pesada da BoNT liga-se a seus receptores nos terminais présinápticos dos neurônios colinérgicos e entra no citoplasma dos neurônios como endocitose, mediada por receptor, onde a ligação dissulfeto entre duas cadeias polipeptídicas de BoNTs desassociam-se e ganham sua forma ativada ${ }^{4} \mathrm{~A}$ cadeia leve se liga para inativar as proteínas, como a proteína associada ao sinaptossoma (SNAP) -25, a proteína de membrana associada à vesícula (VAMP) e a sintaxina que são responsáveis pela fusão do neurotransmissor contendo vesículas com a bicamada lipídica na fenda sináptica, evitando assim a liberação de terminações nervosas polinérgicas, parassimpáticas e simpáticas pós-ganglionares de acetilcolina (ACh) Apresenta sete tipos diferentes nomeados de $A$ a $G$ e tem ação sobre a musculatura voluntária através da inibição da liberação de acetilcolina nas junções neuromusculares ${ }^{5}$ Os diferentes tipos de toxinas, interferem, especificamente, com diferentes proteínas envolvidas no acoplamento, fixação e fusão das vesículas sinápticas e da membrana pré-sináptica ${ }^{6}$.

Sendo assim, através de uma quimiodesnervação, a neurotoxina botulínica (BoNT) se tornou um dos agentes terapêuticos mais polivalentes na medicina moderna. Com diversas aplicações clínicas, o uso da neurotoxina botulínica tem se expandido durante as últimas três décadas, com uma expansão para parte cosmética. A melhor compreensão das complicações causadas pelo uso desta neurotoxina será, primordial para adequação às necessidades e condições dos pacientes.

Revisar a literatura abordando os efeitos adversos decorrentes do uso terapêutico e cosmético da TB.

\section{REVISÃO DAS COMPLICAÇÕES}

Em relação a medicina estética, desde 2008, o FDA tem advertido sobre doses de BoNTA não controladas, utilizadas de forma aleatória, com complicações pelo halo de ação da toxina. ${ }^{7}$

As complicações estéticas mais relatadas estão associadas a diluições incorretas, aplicações em áreas não recomendadas, massagens na área de aplicação pós procedimento imediato, erro de técnica com o posicionamento inadequado da agulha e /ou erro na dose de BoNTA ${ }^{8}$

O hiper lacrimejamento pode ocorrer e sincinesia, quando o uso da BoNTA, após paralisia facial, por uso excessivo da substância ${ }^{8}$

A elevação excessiva da cauda do supercílio é a mais comum complicação, com cerca de $33 \%$ dos casos relatados. Ocorre principalmente por variações anatômicas ou com musculatura frontal vigoroso ou supercílios desarmônicos. É um efeito indesejável e esteticamente prejudicial a harmonização facial. Ocorre por uma ação compensatória da porção lateral do músculo frontal quando toda a região central da testa e glabela estiver paralisada ${ }^{9}$. 
Devido a rica vascularização da face, eritema e hematoma ocorrem em cerca de $25 \%$ das complicações são comuns e estão relacionados a ruptura da pequena irrigação cutânea, por trauma da própria agulha ao ser realizado o procedimento. ${ }^{10}$

A ptose palpebral com alteração do arco superior da íris foi relatada em cerca de $15 \%$ dos casos. Esta complicação está relacionada à aplicação da BoNT na região da glabela e fronte ou pela aplicação no septo orbital, causando paralisia do músculo levantador da pálpebra superior. Os sintomas aparecem após 7 a 10 dias da aplicação. Todos os pacientes podem apresentar certo grau de dor ou desconforto com a aplicação. Ptose palpebral é a complicação mais frequente e é resultante da passagem da toxina pelo septo orbitário, tanto por difusão quanto por aplicação inadvertida. A incidência média foi de 13,4\%, segundo $\operatorname{Dutton}^{(4)}$.

Uma complicação, também comum ( $9 \%$ dos casos relatados), é a ptose do lábio superior consequente da paralisia do músculo levantador do lábio superior e/ou zigomático maior. Esta complicação acontece quando a BoNT é aplicada na região infraorbitária ou malar, para correção das rugas da pálpebra inferior, das rugas zigomáticas, da hipertrofia do músculo orbicular e na região nasal para correção do "sinal da toxina botulínica". ${ }^{10}$

Erros técnicos, como aplicações fora das áreas não recomendadas ou superdosagem na região do mento e nos depressores do ângulo da boca, ocasionam dificuldade na movimentação do lábio inferior, além das alterações labiais inestéticas durante o sorriso. Estas alterações causam prejuízo das funções da boca, como mordedura involuntária da língua e modificação da fala, além de parestesia dos lábios, perda do desenho do filtro, dificuldade de movimentação da saliva na boca e perda de saliva durante a fala, o que cria desconforto ao paciente e situação inestéticas aos mesmos. ${ }^{10}$ Não se pode deixar de citar o posicionamento inadequado ou falha na dose de toxina botulínica, podendo resultar em perda de expressão facial e desfigurações ${ }^{8}$.

Reações generalizadas, incluindo náusea, mal-estar, sintomas semelhantes aos da gripe e erupções cutâneas, podem resultar da difusão da neurotoxina na circulação sistêmica e são tratadas de forma terapêutica com base nos sintomas. As reações sistêmicas são consideradas hipersensibilidade à BoNT ou a um dos componentes (ou seja, albumina ou lactose) na suspensão. As alergias são raras, mas foram relatados relatos de casos de erupção fixa por medicamento, reação anafilática localizada na perna e desenvolvimento de nódulos sarcóides por estimulação antigênica após a injeção ${ }^{11}$

O eritema, dor, equimose, ptose palpebral e superciliar, ptose do lábio superior, elevação excessiva da cauda do supercílio estão amplamente descritos na literatura especializada. Contudo, atualmente, devido ao uso indiscriminado na estética e muitas vezes associadas a uma técnica inapropriada, as toxinas botulínicas (BoNTs), passaram a ser consideradas substâncias com um grande 
poder nocividade aos seres humanos, quando não respeitado os protocolos. ${ }^{12}$. Os tipos de BoNT A, B, E e F têm sido diretamente relacionados a doenças humanas letais ${ }^{13}$, sendo a toxina A, a mais empregada no uso estético.

Entre os efeitos, com potenciais maléficos aos seres humanos, estão a paralisia muscular e a morte que são mediados pelos bloqueios da BoNT na liberação de ACh e subsequente parada na via de sinalização colinérgica nas junções sinápticas. ${ }^{11}$ Outros sintomas relacionados a intoxicação BoNTs, podem variar xerose ocular e oral, tosse, retenção urinária, variações da pressão arterial, arritmias cardíacas, fadiga e dispneia ${ }^{14}$

A cefaleia e as náuseas, até então associadas apenas ao quadro de ansiedade da paciente ${ }^{10}$, atualmente estão associadas a doses incorretas e a trauma no injetar, atingindo o periósteo ${ }^{15}$

Outra preocupação crescente no meio médico é a formação de anticorpos. Apesar do uso clínico da BoNTA ser através da administração local, sua presença na corrente sanguínea tem sido relatada, através das técnicas de ELISA (enzyme-linked immunoabsorbent assay) ou RIA (radioimmunoassay). As aplicações frequentes em intervalos curtos e a alta carga proteica associada à BoNT, nas formas comercialmente disponíveis do produto, aumentam o risco de desenvolvimento de anticorpos neutralizantes ${ }^{16}$.Quando anticorpos contra a BoNT são formados, a duração da ação e a duração máxima dos efeitos terapêuticos são usualmente reduzidas constituindo a falha terapêutica parcial ${ }^{17}$.

A resposta fisiológica a este efeito, está na imunogenicidade, que é à capacidade de um produto de proteína induzir a formação de anticorpos e a não resposta secundária, que descreve o situação em que um paciente inicialmente responde à terapia, mas perde a responsividade clínica ao longo do tempo com repetidos tratamentos ${ }^{17}$.

A não resposta primária ocorre, quando um paciente não responde ao primeiro e a qualquer administração de uma terapia. O primeiro pode ser devido à formação de anticorpos neutralizantes; no entanto, a presença de tais anticorpos nem sempre prediz a não resposta ao tratamento, uma vez que pelo menos alguns pacientes com neutralização os anticorpos retêm a sensibilidade normal às neurotoxinas botulínicas ${ }^{18}$.

A diplopia também tem sido relatada como uma complicação oftálmica da aplicação de BoNTA Apesar de rara e transitória que está relacionada à quimiodenervação de grupos musculares adjacentes ${ }^{19}$.

Outros efeitos colaterais, com uma variedade de reações cutâneas, pouco relatados, são as reações exantemáticas, edema, prurido, alteração na cor da pele no local da injeção, erupção psoriasiforme e reações anafiláticas ${ }^{20}$. Granuloma sarcoidal também foi relatado após injeção de BoNTA ${ }^{21}$ Várias marcas de BoNTA foram relatadas como causadoras de reações bizarras ${ }^{22}$ As diferenças entre os produtos incluem desde o processo de fabricação, até os métodos de ensaio usados para determinar 
unidades de atividade biológica. Essas diferenças resultam em um conjunto específico de interações entre cada produto BoNTA e o tecido injetado ${ }^{23}$. Consequentemente, os produtos mostram diferenças em seus perfis e houve um relato recente de reação alérgica grave causada pela injeção de toxina botulínica chinesa A para tratar rugas faciais ${ }^{24}$

O mecanismo pelo qual BoNTA induz a reação alérgica grave é pouco conhecido, sendo que o potencial alérgico imunológico da própria toxina, possa induzir a reação alérgica, o efeito da albumina sérica humana ou gelatina adicionada à toxina também pode estimular da reação imunológica 24.

Outros sintomas, mais raros e basicamente revelados por neurologistas e outros especialistas que utilizam maiores doses de TB, são: ectrópio, ceratoconjuntivite, visão borrada ou dupla, alterações musculares decorrentes de má aplicação, sensação de corpo estranho nos olhos, estrabismo não corrigido com lacrimejamento, fraqueza muscular, parestesias, fadiga e boa seca 25

Pouco discutido, mas não menos importante, o armazenamento da BoNTA por um profissional não médico, assim como reaproveitamento fora dos padrões específicos de cada laboratório, a possibilidade de contaminação ou reação a produtos aditivos não padronizados, como gelatina ou sacarose $^{26}$.

No entanto, a maioria destes efeitos, tanto locais quanto sistémicos, são temporários, o conhecimento farmacológico, técnico, além da administração com menor número de doses e em quantidade mínima necessária da toxina é fundamental para que, os efeitos cumulativos da toxina no sistema neuromuscular, possam ser minimizados ${ }^{27}$.

Em conclusão, os médicos envolvidos nos procedimentos injetáveis com toxina botulínica, devem estar tecnicamente aptos a reconhecer e intervir, nas possíveis complicações, pois algumas delas podem causar reações graves e inestéticas aos pacientes. 


\section{REFERENCIAS}

1. Johnson EA. Biomedical aspects of Botulinum toxin. J. Toxicol- Toxin Reviews 1999;18(1):1-15.

2. Pirazzini M, Rossetto O, Eleopra R, Montecucco C. Biological Actions of Botulinum Neurotoxins Pharmacological Reviews April 1, 2017, $69 \quad$ (2) 200-235; DOI: https://doi.org/10.1124/pr.116.012658

3. Poulain B, MR.Popoff. Neurotoxine botulique : mécanismes moléculaires et cellulaires de son action sur le système nerveux, Bulletin de l'Académie Nationale de Médecine, 10.1016/j.banm.2020.01.022, (2020).

4. Hassaan, H. Bashir, Joseph Jankovic, Treatment of Tardive Dyskinesia, Neurologic Clinics, 10.1016/j.ncl.2020.01.004, (2020).

5. Zornetta I, Azarnia, Tehran D, Arrigoni G, Anniballi F, Bano L, Leka O, et al. The first non Clostridial botulinum-like toxin cleaves VAMP within the juxtamembrane domain. Sci Rep 20166:30257.

6. Wheeler A and Smith HS Botulinum toxins: mechanisms of action, antinociception and clinical applications. Toxicology $2013-306: 124-146$

7. Carruthers JDA, Carruthers JA. Treatment of glabellar frown lines with C. botulinum-A exotoxin. J Dermatol Surg Oncol 1992;18: 17-21.

8. Jankovic J. Treatment of cervical dystonia with botulinum toxin. Mov. Disord. 2004;19(Suppl. 8):S109-S115.

9. Santos, TJ. Aplicação da toxina Botulínica em Dermatologia e estética e suas complicações: Revisão da Literatura. (2013) Trabalho de obtenção de título de pós-graduação em Dermatologia Núcleo Alfenas.

10. Maio, M. Tratado de Medicina Estética. 2011 .2.ed, v.2, São Paulo: Roca.

11. Assmann T, Krahl D, Mang R. Cutaneous sarcoidal granuloma after botulinum toxin type A injection. J Am Acad Dermatol. 2013;69:e247-9

12. Setler PE - Therapeutic use of botulinum toxins: background and history. Clin J Pain 2002;18(6 suppl):s119-124.

13. Uwe W, Mühlenhoff C, Benecke R, Dressler D, Mix E,Alt J et al Frequency and risk factors of antibody-induced secondary failure of botulinum neurotoxin therapy Neurology May 2020, 94 (20) e2109- e2120; DOI: 10.1212/WNL.0000000000009444

14. Santos, JS; Pignata V, Costa M. Epidemiologia e fatores de riscos relacionados à intoxicação alimentar causada por Clostridium Botulinum: Uma revisão narrativa. Clinical \& Biomedical Research, [S.1.], v. 39, n. 2, aug. 2019. ISSN 2357-9730. Available at: <https://www.seer.ufrgs.br/hcpa/article/view/85961>. Date accessed: 16 sep. 2020.

15. Cardoso $\mathrm{F}$ - Toxina botulínica tipo $\mathrm{B}$ no manejo de distonia não responsiva à toxina botulínica tipo A. Arq Neuropsiquiatr 2003;61: 607-610

16. Mejia NI, Vuong KD, Jankovic J - Long-term botulinum toxin efficacy, safety and immunogenicity. Mov Disord 2005;20:592-597

17. Comella CL - Interim results of an observation study of neutralizing antibody formation with the current preparation of botulinum toxin type A treatment for cervical dystonia. Neurology 2004;62:6141 
18. Atassi MZ, Dolimbek BZ, Jankovic J, Steward LE, Aoki KR Regions of botulinum neurotoxin A light chain recognized by human anti-toxin antibodies from cervical dystonia patients immunoresistant to toxin treatment. The antigenic structure of the active toxin recognized by human antibodies. Immunobiology.2011. 216:782-792.

19. Sheen-Ophir S, Almog Y. Harefuah. 2013;152(2):98-122

20. Bowden JB, Rapini RP. Psoriasiform eruption from intramuscular botulinum A toxin. Cutis. 1992;50:415-6

21. Namazi N, Najar Nobari N. J Cosmet Dermatol. 2020; 19(8):1936-1939.

22. Pickett A, Mewies M. Serious issues relating to the clinical use of unlicensed botulinum toxin products. J Am Acad Dermatol. 2009;61:149-50 .

23. Brin MF, James C, Maltman J. Botulinum toxin type A products are not interchangeable: a review of the evidence. Biologics. 2014;8:227-241.

24. Careta MF, Delgado L, Patriota R. Report of allergic reaction after application of botulinum toxin. Aesthet Surg J. 2015;35:102-5.9.

25. Kede, MPV.; Sabatovich, O. Dermatologia Estética. $2^{\mathrm{a}}$ ed, Ed.Atheneu. Rio de Janeiro, 2009,p.563-580.

26. Silva, KCCl. Reação alérgica após aplicação toxina botulínica. Revista da Faculdade de Ciências Médicas de Sorocaba, [S.1.], nov. 2018. ISSN 1984-4840. Disponível em: <https://revistas.pucsp.br/RFCMS/article/view/40042>. Acesso em: 16 set. 2020.

Sposito MMM. Toxina botulínica do tipo A: mecanismo de ação. Acta Fisiatr. 2009;16(1):25-37. 